\title{
MENINGKATKAN MOTIVASI SISWA MELALUI PENERAPAN SMALL SIDED GAMES
}

\author{
Mochamad Ridwan \\ Universitas Negeri Surabaya, Indonesia \\ Email: mochamadridwan@unesa.ac.id
}

Received: 26 April 2020; Accepted 16 July 2020; Published 29 November 2020

Ed 2020; 5(2): 155-163

\begin{abstract}
ABSTRAK
Siswa merasa jenuh jika pendekatan mengajar yang diberikan oleh guru secara monoton dan tidak ada perubahan. Penting bagi guru PJOK untuk memberikan variasi dalam proses pembelajaran khususnya pendekatan mengajar. Tujuan dalam penelitian ini yaitu ingin mengetahui tingkat motivasi siswa dalam materi sepakbola dengan diterapkannya small sided games. Metode penelitian yang digunakan yaitu penelitian deskriptif kuantitatif dengan pendekatan survei jenis school survey serta teknik pengumpulan data menggunakan angket yang disebar kepada 49 siswa. Dianalisis menggunakan statistik deskriptif dengan tahap editing, coding dan scoring. Hasil dalam penelitian didapatkan yaitu 4.1\% (2) siswa yang memiliki motivasi sangat rendah, 28.6\% (14) siswa yang memiliki motivasi rendah, 36.7\% (18) siswa yang memiliki motivasi cukup, $18.4 \%$ (9) siswa yang memiliki movitasi tinggi, dan $12.2 \%$ (6) siswa yang memiliki motivasi sangat tinggi dalam mengikuti materi sepakbola. Kesimpulan dalam penelitian ini yaitu menunjukan bahwa dengan diberikannya small sided games, motivasi siswa mengikuti materi sepakbola berada pada kategori cukup. Selain itu, disarankan untuk melakukan penelitian dengan jumlah sampel yang lebih banyak dan bervariasi dengan jenjang yang berbeda agar ditemukan solusi lain dalam memecahkan permasalahan.
\end{abstract}

Kata Kunci: Small Sided Games; Motivasi; Sepakbola; Pendidikan Jasmani

\section{IMPROVING STUDENT MOTIVATION THROUGH THE IMPLEMENTATION OF SMALL SIDED GAMES}

\begin{abstract}
Students feel bored when the teaching approach is monotonous and unchanging, making it essential for Physical Education, Sports, and Health (PJOK) teachers to provide variations in the learning process. Therefore, this study aims to determine student motivation in football material by implementing smallsided games. A descriptive and quantitative research method with a school survey approach was employed, while the data was collected by using questionnaires distributed to 49 students. Then, data analysis was performed by using descriptive statistics in the editing, coding, and scoring stages. The results showed that two and four students had $4.1 \%$ and $28.6 \%$, meaning they had very low and low motivation to follow the football material. Eighteen students scored $36.7 \%$, nine had $18.4 \%$, while six scored $12.2 \%$, which means they had sufficient, high, and very high motivation. Therefore, the study results concluded that giving small-sided games made students' motivation to follow football material more suitable. Furthermore, a study with more extensive and varied sample sizes was recommended to discover other solutions to the problem.
\end{abstract}

Keywords: Small Sided Games; Motivation; Football; Physical Education

Copyright @ 2020, Journal Sport Area

DOI: https://doi.org/10.25299/sportarea.2020.vol5(2).4873

How To Cite: Ridwan, M. (2020). Meningkatkan Motivasi Siswa Melalui Penerapan Small Sided Games. Journal Sport Area, 5(2), 155-163. 


\section{PENDAHULUAN}

Masalah pendidikan di Indonesia apabila ditinjau dari sisi kualitas Sumber daya manusia masih jauh tertinggal dibandingkan dengan Negara lain (Kurniawan, 2016). Sumber daya manusia menjadi salah satu aspek yang harus diperbaiki dan ditingkatkan untuk taraf pendidikan yang lebih baik. Saat ini sumber daya manusia khususnya guru di setiap jenjang kelayakan mengajar belum begitu baik seperti hasil penelitian Aji dan Winarno (2016) yaitu guru yang layak untuk mengajar di SMA Negeri sebesar 65,29\% dan 64,73\% untuk SMA Swasta. Ini menjadi tantangan besar bagi pelaku di dalamnya untuk merubah ke arah lebih baik. Pendidikan merupakan usaha sadar untuk mempengaruhi siswa agar mampu mengembangkan dan mengaktualisasikan potensipotensi yang dimiliki agar mampu menjalani hidup dengan sebaik-baiknya (Utama, 2011). Banyak isu permasalahan yang terjadi khususnya terkait pendidikan jasmani, diantaranya adalah status terbawah, standar kompetensi profesional yang rendah, alokasi waktu yang tidak sesuai, alokasi dana, ketenagaan, mutu proses belajar dan mengajar (PBM), evaluasi, kegiatan ekstrakulikuler, dan identifikasi serta pengembangan bakat olahraga jalur persekolahan (Ginanjar, 2015).

Selain itu, dalam dunia pembelajaran kita, dewasa ini merupakan bagaimana upaya pembelajaran serta pengajaran di sekolah dapat membagikan sumbangan berarti pada kenaikan mutu manusia Indonesia. Lingkup mikro pendidikan, terjalin pula perpindahan metode serta style mengajar guru, yakni dari metode serta model pengasuhan dan pengembangan nilai-nilai yang dibutuhkan sebagai penanaman rasa cinta gerak dalam ajang sosialisasi, berganti menjadi pola pelatihan berolahraga dengan tujuan utama menjadikan anak terampil olahraga (Mahendra, 2014). Selain itu, banyak guru penjas bukan berasal dari pendidikan olahraga, dan harus merangkap memberikan mata pelajaran lain (Rustiana, 2013).

Pendidikan jasmani merupakan mata pelajaran yang dominan dilaksanakan di luar kelas, sehingga siswa dapat mengekspresikan dengan bebas khususnya melalui gerak. Pendidikan jasmani sebagai salah satu mata pelajaran yang disajikan di sekolah, mengenakan kegiatan fisik dengan persentase yang lebih banyak digunakan sebagai media pendidikan, hingga proporsi psikomotor lebih banyak proporsinya dalam pendidikan pembelajaran jasmani dibandingkan dengan kawasan kognitif serta afektif (Yuliawan, 2016). Pembelajaran Pendidikan jasmani pada dasarnya ialah pembelajaran lewat kegiatan jasmani untuk menggapai pertumbuhan pribadi secara merata (Setiawan, 2017). Pendidikan jasmani yang diberikan di sekolah memiliki tujuan supaya siswa ataupun peserta didik mempunyai pengetahuan serta keahlian dalam berolahraga yang mencakup aspek kognitif, afektif, serta psikomotor. Pendidikan jasmani ialah media untuk mendesak pertumbuhan keahlian motorik, keahlian fisik, pengetahuan, penalaran serta pembiasaan pola hidup sehat yang bermuara untuk memicu perkembangan dan pertumbuhan yang sepadan (Priyanto, 2013). Pembelajaran yang menggunakan kegiatan jasmani yang sudah direncanakan sebelumnya secara tertib dengan mempunyai tujuan untuk meningkatkan sebagian aspek seperti kesehatan, kebugaran jasmani, penguasaan gerak serta berpikir kritis dan mempunyai stabilitas emosi (Aji \& Winarno, 2016). Berdasarkan pendapat di atas dapat disimpulkan bahwa pendidikan jasmani adalah pendidikan melalui aktivitas jasmani yang memiliki tujuan bagi siswa dalam segi kognitif, afektif dan psikomotor agar memiliki kebugaran jasmani dan pembiasaan pola hidup sehat. Pelaksanaan pembelajaran penjas di setiap jenjang melibatkan macammacam olahraga permainan, salah satunya adalah sepakbola. Sepakbola adalah salah satu cabang olahraga yang memiliki daya tarik tersendiri bagi masyarakat Indonesia 
dibandingkan olahraga lainnya (Putra, Sudjana, \& Amiq, 2016). Sepakbola merupakan salah satu olahraga yang popular di dunia yang disenangi dan menarik minat masyarakat terlepas dari faktor usia, jenis kelamin, dan faktor sosial (Gema \& Rumini, 2016).

Sepakbola sudah banyak hadapi pergantian serta pertumbuhan dari wujud sederhana serta primitif hingga jadi permainan sepakbola modern yang sangat digemari banyak orang, tua-muda, kanak-kanak apalagi perempuan (Komarudin, 2013). Pada saat siswa berada di sekolah, bakat dan ketertarikan dapat disalurkan melalui materi yang ada di dalamnya sesuai dengan kurikulum yang telah ditetapkan Pemerintah. Peran guru dalam proses pembelajaran memiliki peran yang sentral. Seorang guru penjas harus kreatif dalam mengajar keterampilan gerak dan permainan dan metode mengajar yang bervariasi agar pembelajaran dapat berlangsung dengan baik dan memudahkan anak dalam pencapaian tujuan pembelajaran (Manalu, 2017). Agar penyampaian dapat maksimal diterima oleh siswa, maka harus menggunakan metode yang tepat disesuaikan dengan situasi dan kondisi dimana pembelajaran itu dilaksanakan. Salah satu metode yang dapat digunakan dalam pemberian materi sepakbola adalah Small Sided Games. Small Sided Games, pada umumnya digunakan untuk bermain sepak bola untuk usia dibawah 15 tahun bertujuan meningkatkan teknik dan taktik, juga digunakan untuk usia 15 tahun ke atas bertujuan untuk mengembangkan kinerja daya tahan aerobik intensitas tinggi (Köklu, Asci, Koçak, Alemdaroglu, \& Dünda, 2011). Selain itu Small Sided Games memiliki potensi untuk mengembangkan kemampuan fisik dan teknis (Dellal, Hill-Haas, Lago-Penas, \& Chamari, 2011). Small sided games juga cocok untuk usia anak-anak seperti dijelaskan oleh Komarudin (2013) ialah small sided games sangat berguna untuk anak, banyak riset serta observasi sudah dicoba untuk menampilkan kalau kanak- kanak memperoleh kesenangan serta belajar lebih banyak serta bermain dalam small sided games dengan ketentuan yang disesuaikan. Metode small sided games ini biasa digunakan oleh para pelatih dalam mengaplikasikan keilmuannya kepada atletnya untuk belajar menyesuaikan strategi dan taktik di lapangan dengan menggunakan bagian lapangan yang kecil. Penelitian ini yang membedakan dengan penelitian lainnya adalah metode ini digunakan dalam proses pembelajaran PJOK dengan menggunakan fasilitas yang ada di sekolah. Sarana dan prasarana yang ada di setiap sekolah berbeda sehingga memanfaatkan apa yang ada. Pemberian small sided games dapat meningkatkan motivasi dan mood positif pemain dibandingkan dengan metode lainnya (Selmi, Ouregui, Levitt, Nikolaidis, Knechtle, \& Bouassida, 2020). Small sided games juga dapat meningkatkan motivasi siswi dalam pembelajaran PJOK sebesar 6.08 \% (Darmawan, Ridwan, \& Herdyanto, 2019). Tujuan dalam penelitian ini yaitu ingin mengetahui tingkat motivasi siswa dalam materi sepakbola dengan diterapkannya small sided games.

\section{METODE PENELITIAN}

Metode penelitian yang digunakan yaitu penelitian deskriptif kuantitatif dengan pendekatan survei serta pengambilan data menggunakan angket. Angket ini disusun dengan mengenakan skala likert dengan 5 motif jawaban yakni sangat setuju (SS), Setuju ( S), ragu- ragu (R), tidak setuju (TS), serta sangat tidak setuju (STS). Tiap butir diberikan skor dengan angka 5 hingga 1 apabila persoalan angket positif serta kebalikannya skor 1 hingga 5 apabila negatif. Proses pengumpulan data dengan cara mendatangi tempat penelitian, menyampaikan maksud dan tujuan serta menjelaskan tata cara pengisian angket yang dibagikan kepada responden. Teknik pengumpulan data one case study di antaranya adalah metode dokumentasi yang digunakan untuk 
mengumpulkan daftar nama sampel yang akan digunakan untuk objek penelitian. Setelah selesai lalu mengelompokkan angket, hasilnya diberi skor dan dianalisis. Angket dalam penelitian ini dilihat dari sudut pandang cara menjawabnya termasuk angket tertutup. Kisi-kisi angket ini terdiri dari motivasi intrinsik yaitu kesenangan, minat, prestasi dan perhatian, sedangkan untuk motivasi ekstrinsik yaitu guru, teman, sarana dan orangtua. Angket dalam penelitian ini mengadopsi dari (Novitasari \& Darmawan, 2019) dengan nilai validitas sebesar 0.323 dan reliabilitas sebesar 0.952 digunakan untuk mengungkap motivasi siswa mengikuti materi sepakbola dalam pendidikan jasmani. Pelaksanaan materi sepakbola menggunakan small sided games dilakukan sesuai dengan jam mata pelajaran sekolah selama 2 x 45 menit. Sampel dalam penelitian ini sebanyak 49 siswa. Desain penelitian yang digunakan adalah one case study. Proses penelitian yang dilakukan dalam membuat artkel ini menggunakan langkah-langkah seperti mengidentifikasi masalah yang terjadi, studi literatur yang sesuai dengan permasalahan, menyusun alat obeservasi dan pengukuran terhadap instrument yang diberikan, menyebarkan angket kepada sampel dan melakukan analisa statistik yang sesuai. Teknik analisis data yang digunakan adalah uji validitas dan reliabilitas untuk lembar kuesioner, lalu analisis data terakhir menggunakan uji normalitas dan uji beda.

\section{HASIL DAN PEMBAHASAN}

Ketika usia anak-anak mendapatkan pengalaman dengan olahraga, anak-anak dapat mengembangkan dan memperbaiki struktur pengetahuan dan keterampilan motorik tertentu, yang membuat mereka secara teknis dan taktis lebih kompeten dalam kinerja permainan mereka (Almeida, Ferreira, \& Volossovitch, 2013). Keterampilan motorik yang baik akan dapat memudahkan seorang dalam belajar penguasaan gerak. Keterampilan motorik ialah kualitas keahlian seorang (orang) dalam melaksanakan gerakan yang dipandang sebagai landasan keberhasilan untuk menyelesaikan penguasaan gerak (Asnaldi, Zulman, \& Madri, 2018). Oleh karena itu dalam penjas harus banyak diberikan keterampilan motorik agar gerak siswa lebih baik. Berikut adalah hasil penghitungan motivasi siswa yang telah diolah dan dianalis menggunakan SPSS versi 21 Agar lebih jelas, dideskripsikan melalui tabel 1.

Tabel 1. Deskripsi Data Motivasi Siswa

\begin{tabular}{cc}
\hline Deskripsi data & Nilai \\
\hline Mean & 122.5 \\
Standar Dev & 14.40 \\
Min & 89 \\
Max & 152 \\
\hline
\end{tabular}

Berdasarkan tabel di atas dapat disimpulkan bahwa nilai rata-rata yang diperoleh sebesar 122.5, standar deviasi sebesar 14.40, nilai minimal yang didapatkan sebesar 89 dan nilai maksimal yaitu 152. Data di atas berfungsi sebagai data awal untuk mengolah data pada tahap berikutnya. Langkah berikutnya adalah dengan membuat interval dari nilai minimal dan maksimal yang telah diperoleh, sehingga muncul kriteria motivasi siswa yang dapat dilihat pada tabel 2. 
Tabel 2. Motivasi Mengikuti Materi Sepakbola

\begin{tabular}{ccccc}
\hline & Freq & \% & Valid & Cum \\
\hline Sangat Rendah & 2 & 4.1 & 4.1 & 4.1 \\
Rendah & 14 & 28.6 & 28.6 & 32.7 \\
Cukup & 18 & 36.7 & 36.7 & 69.4 \\
Tinggi & 9 & 18.4 & 18.4 & 87.8 \\
Sangat Tinggi & 6 & 12.2 & 12.2 & 100.0 \\
\hline Total & $\mathbf{4 9}$ & $\mathbf{1 0 0 . 0}$ & $\mathbf{1 0 0 . 0}$ & \\
\hline
\end{tabular}

Menarik untuk dicermati bahwa masing-masing siswa memiliki ketertarikan dalam pembelajaran PJOK yang tidak dapat dipaksakan, khususnya motivasi dalam mengikuti materi sepakbola. Setelah adanya data yg dijabarkan di atas, dan sesuai dengan tujuan penelitian ini yaitu mengetahui tingkat motivasi siswa dalam mengikuti materi sepakbola dengan diterapkannya small sided games, maka tabel 2 menunjukkan pada setiap kategori terdapat siswa dengan motivasi yang berbeda-beda. Pada kategori motivasi sangat rendah terdapat 2 siswa, kategori motivasi rendah terdapat 14 siswa, kategori motivasi cukup terdapat 18 siswa, kategori motivasi tinggi terdapat 9 siswa dan kategori motivasi sangat tinggi terdapat 6 siswa. Ini menjadi tantangan bagi guru untuk dapat memberikan yang lebih baik lagi agar tidak ada siswa yang berada pada kategori motivasi sangat rendah dan rendah. Selain itu, guru juga harus dapat mempertahankan motivasi siswa yang cukup, tinggi dan sangat tinggi agar tujuan yang telah ditetapkan dapat tercapai. Motivasi adalah proses yang memberi semangat, arah dan kegigihan perilaku. Artinya perilaku yang termotivasi adalah perilaku yang penuh energi, terarah dan bertahan lama (Setiawan, Murti, \& Suriyasa, 2013). Motivasi merupakan salah satu komponen penting dalam pencapaian prestasi siswa dalam pembelajaran (Wibowo, 2017).

Guru sebagai seorang pendidik harus memiliki peranan yang penting, karena dalam melaksanakan pembelajaran efektif guru hendaknya bisa menerapkan strategi pembelajaran yaitu memprioritaskan daripada tujuan pembelajaran, mengevaluasi kegiatan pembelajaran dan merencanakan, memotivasi serta pengendalian jiwa peserta didik, dan juga guru dapat menentukan sikap sehingga bisa menghasilkan siswa yang berwawasan positif terhadap perkembangan dirinya sendiri/peserta didik (Mahardhika, Betty, Jusuf, \& Priyambada, 2018). Ketika siswa memiliki motivasi, maka materi yang disampaikan oleh guru pada saat pembelajaran pendidikan jasmani akan mudah diterima. Diketahui bahwa materi yang ada pada pendidikan jasmani terdapat aktivitas jasmani dan mengandung unsur permainan. Seperti yang diungkapkan oleh Utama (2011) yaitu pendidikan jasmani merupakan salah satu usaha sadar untuk menciptakan lingkungan yang mampu mempengaruhi potensi peserta didik agar berkembang ke arah tingkah laku yang positif melalui aktivitas jasmani. Melalui bermain anak akan akan terbiasa dengan tekanan-tekanan baik dari dirinya sendiri maupun dari luar sehingga akan mampu mengelola emosi, kecemasan dan rasa percaya diri dengan baik. 


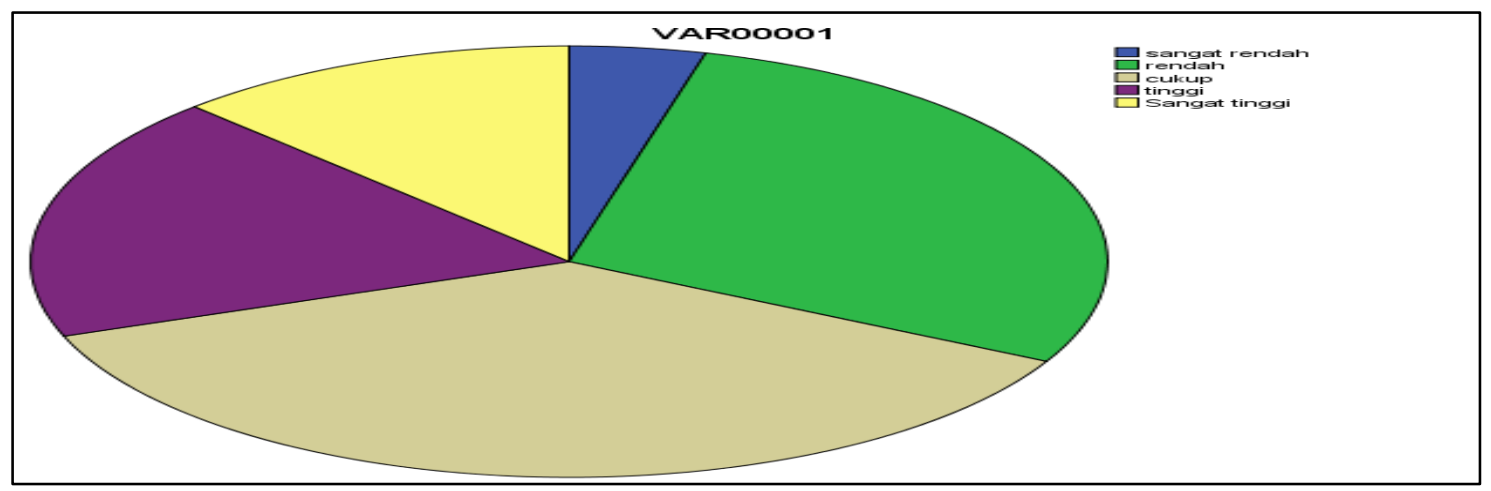

Gambar 1. Diagram Kategori Motivasi

Berdasarkan data-data di atas, salah satu cara untuk meningkatkan motivasi siswa mengikuti materi sepakbola yaitu dengan metode small sided games. Metode ini dapat disesuaikan dengan situasi dan keadaan sekolah. Small sided games di dalamnya terdapat unsur bermain sehingga siswa tidak merasa jenuh dengan materi yang diberikan. Bermain salah satu cara siswa belajar mengekspresikan hasil pemikiran melalui lingkungan sekitar, sehingga siswa akan menemukan berbagai pengalaman salah satunya pengalaman gerak (Asriansyah, 2018). Metode small sided games banyak memiliki keuntungan dari segi kebugaran jasmani dan penguasaan keterampilan dasar sepakbola. Terpenuhinya metabolisme anaerob sebagai kebutuhan energi otot secara intens (Köklu et al., 2011). Rata-rata meningkatkan denyut jantung lebih tinggi secara signifikan (Hulka, Weisser, \& Belka, 2016). Memungkinkan lebih banyak waktu mengelola bola dalam kondisi seperti permainan (Halouani, Chtourou, Gabbett, Chaouachi, \& Chamari, 2014). Small-sided games merupakan proses latihan dengan lapangan skala kecil yang bertujuan untuk meningkatkan teknik dan taktik dalam permainan sepakbola (Wardana, Setiabudi, \& Candra, 2018).

\section{KESIMPULAN}

Merujuk dari data yang didapatkan, kesimpulan dalam penelitian ini menunjukan bahwa dengan diberikannya small sided games, motivasi siswa mengikuti materi sepakbola berada pada kategori cukup. Untuk penelitian selanjutnya agar dapat memiliki banyak data akan diteliti small sided games terkait kebugaran jasmani, teknik dan hasil belajar dengan jumlah sampel yang lebih besar dan berbeda jenjang pendidikan. Tidak menutup kemungkinan penelitian ini dapat digunakan di luar pembelajaran sekolah seperti ekstrakurikuler atau klub. Keterbatasan dalam penelitian ini tidak diberikannya perlakukan secara khusus (treatment) selain itu jumlah sampel masih sedikit.

\section{DAFTAR PUSTAKA}

Aji, B. S., \& Winarno, M. E. (2016). Pengembangan Instrumen Penilaian Pengetahuan Mata Pelajaran Pendidikan Jasmani Olahraga dan Kesehatan (PJOK) Kelas VIII Semester Gasal. Jurnal Pendidikan, 1(7), 1449-1463. http://dx.doi.org/10.17977/jp.v1i7.6594 
Almeida, C. H., Ferreira, A. P., \& Volossovitch, A. (2013). Offensive sequences in youth soccer: Effects of experience and small-sided games. Journal of Human Kinetics, 36(1), 97-106. https://doi.org/10.2478/hukin-2013-0010

Asnaldi, A., Zulman, \& Madri, M. (2018). Hubungan Motivasi Olahraga dan Kemampuan Motorik Dengan Hasil Belajar Pendidikan Jasmani Olahraga dan Kesehatan Siswa Sekolah Dasar Negeri 16 Sintoga Kecamatan Sintuk Toboh Gadang Kabupaten Padang Pariaman. Jurnal MensSana, 3(2), 16-27. https://doi.org/10.24036/jm.v3i2.75

Asriansyah, A. (2018). Pengembangan Permainan Tradisional Untuk Melestarikan Budaya Bangsa Melalui Pembelajaran Pendidikan Jasmani Sekolah Dasar. Jurnal Pendidikan Jasmani dan Olahraga, 3(1), 82-88. https://doi.org/10.17509/jpjo.v3i1.10597

Darmawan, G., Ridwan, M., \& Herdyanto, Y. (2019, August). Motivation Learning of Football: Application Small Sided Games. In 1st International Conference on Education Social Sciences and Humanities (ICESSHum 2019). Atlantis Press.

Dellal, A., Hill-Haas, S., Lago-Penas, C., \& Chamari, K. (2011). Small-sided games in soccer: amateur vs. professional players' physiological responses, physical, and technical activities. The Journal of Strength \& Conditioning Research, 25(9), 2371-2381. 10.1519/JSC.0b013e3181fb4296

Gema, A. R, \& Rumini, T. S. (2016). Manajemen Kompetisi Sepakbola Sumsel Super League (Ssl) Kota Palembang. Journal of Physical Education and Sport, 5(1), 2-4. https://doi.org/10.5897/JPESM.

Ginanjar, A. (2015). The Influence of Inquiry Method in Motivating the SMP' Students. Jurnal Kependidikan: Penelitian Inovasi Pembelajaran, 45(2), 123-129. https://doi.org/10.21831/jk.v45i2.7489

Halouani, J., Chtourou, H., Gabbett, T., Chaouachi, A., \& Chamari, K. (2014). SmallSided Games In Team Sports Training: A Brief Review. Journal of Strength and Conditioning Research / National Strength \& Conditioning Association, 28(12), 3594-3618. 10.1519/JSC.0000000000000564

Hulka, K., Weisser, R., \& Belka, J. (2016). Effect of the pitch size and presence of goalkeepers on the work load of players during small-sided soccer games. Journal of Human Kinetics, 50(2), 175-181. https://doi.org/10.1515/hukin-2015-0180

Köklu, Y., Asci, A., Koçak, F. Ü., Alemdaroglu, U., \& Dünda, U. (2011). Comparison of the Physiological Responses To Different Small -Sided Games in Elite Young. Strength And Conditioning, 25(6), 1522-1528. 
Komarudin. (2013). Small-Sided Games Sebagai Sarana Untuk Mengembangkan Kemampuan Pengambilan Keputusan Dalam Permainan Sepakbola. Jurnal Pendidikan Jasmani Indonesia, 9(4), 58-63. https://doi.org/10.21831/jpji.v9i1.3064

Kurniawan, R. Y. (2016). Identifikasi Permasalahan Pendidikan di Indonesia Untuk. Konvensi Nasional Pendidikan Indonesia (KONASPI) VIII Tahun, 1415-1420.

Mahardhika, N. A., Jusuf, J. B. K., \& Priyambada, G. (2018). Dukungan Orangtua Terhadap Motivasi Berprestasi Siswa SKOI Kalimantan Timur Dalam Mengikuti Pembelajaran Pendidikan Jasmani. Jurnal Pendidikan Jasmani Indonesia. 14(2), 62-68. https://doi.org/10.21831/jpji.v14i2.23525

Mahendra, A. (2014). Telaah Kritis terhadap Program PGPJ (Pendidikan Guru Pendidikan Jasmani) di Indonesia. Jurnal Atikan. 4(2), 227-238.

Manalu, W. (2017). Pengaruh Metode Pembelajaran dan Motivasi Belajar Terhadap Hasil Belajar Passing Sepakbola. JUARA : Jurnal Olahraga, 2(1), 1-10.

Novitasari, V. F., \& Darmawan, G. (2019). Penerapan Small Sided Games Terhadap Hasil Belajar Passing dan Motivasi Siswi Mengikuti Pembelajaran Sepakbola. Jurnal Pendidikan Olahraga dan Kesehatan, 7(1), 85-88.

Priyanto, A. (2013). Peningkatan Motivasi Belajar Gerak Dasar Lari melalui Pendekatan Bermain dalam Pembelajaran Penjas Siswa Kelas V SD I Donotirto Kretek Bantul. Jurnal Pendidikan Jasmani Indonesia, 9(1), 1-6. https://doi.org/10.21831/jpji.v9i1.3056

Putra, A. U. K., Sudjana, I. N., \& Amiq, F. (2016). Pengaruh Latihan Small Sided Games Terhadap Peningkatan Kemampuan Vo2Max Pemain Sepakbola U-17 Di Persatuan Sepakbola Smuba Junior Kota Batu. Jurnal Pendidikan Jasmani, 25(1), 20-30. http://dx.doi.org/10.17977/pj.v25i1.4886

Rustiana, E. (2013). Upaya Peningkatan Kecerdasan Emosi Siswa Sekolah Dasar Melalui Pendidikan Jasmani Harmoni. Jurnal Cakrawala Pendidikan, 5(1), 139149. https://doi.org/10.21831/cp.v5i1.1267

Selmi, O., Ouergui, I., Levitt, D. E., Nikolaidis, P. T., Knechtle, B., \& Bouassida, A. (2020). Small-Sided Games are More Enjoyable Than High-Intensity Interval Training of Similar Exercise Intensity in Soccer. Open Access Journal of Sports Medicine,11, 77-84. https://doi.org/10.2147/oajsm.s244512

Setiawan, A. (2017). Hubungan Authentic Assessment Dengan Motivasi Belajar Pendidikan Jasmani. JUARA: Jurnal Olahraga, 2(2), 143-150. https://doi.org/10.33222/juara.v2i2.41 
Utama, A. M. B. (2011). Pembentukan Karakter Anak Melalui Aktivitas Bermain Dalam Pendidikan Jasmani. Jurnal Pendidikan Jasmani Indonesia, 8(1), 1-9. https://doi.org/10.21831/jpji.v8i1.3477

Wardana, C. R., Setiabudi, M. A., Candra, A. T., (2018). Pengaruh Latihan Small-Sided Games Terhadap Keterampilan Passing, Controlling dan Shooting Peserta Ekstrakurikuler Sepakbola SMK Negeri 1 Tegalsari Kabupaten Banyuwangi. Jurnal Kejaora (Kesehatan Jasmani dan Olah Raga), 3(2), 194-201.

Wibowo, T. (2017). Survei Motivasi Belajar Siswa Dalam Mengikuti Pembelajaran Jasmani, Olahraga dan Kesehatan Pada Siswa Sma/Ma/Smk Negeri Kelas Xi SeKecamatan Kota Ponorogo. Jurnal Pendidikan Olahraga dan Kesehatan, 5(1), 117-122.

Yuliawan, D. (2017). Pembentukan Karakter Anak Dengan Jiwa Sportif Melalui Pendidikan Jasmani Olahraga dan Kesehatan. Jurnal SPORTIF: Jurnal Penelitian Pembelajaran, 2(1), 101-112. https://doi.org/10.29407/js_unpgri.v2i1.661 